CLINICAL STUDY

\title{
Low prevalence of hypopituitarism after traumatic brain injury: a multicenter study
}

N E Kokshoorn, J W A Smit, W A Nieuwlaat ${ }^{1}$, J Tiemensma, P H Bisschop ${ }^{2}$, R Groote Veldman ${ }^{3}$, F Roelfsema, A A M Franken ${ }^{4}$, M J E Wassenaar, N R Biermasz, J A Romijn and A M Pereira

Department of Endocrinology and Metabolic Diseases C4-R, Leiden University Medical Center, PO Box 9600, 2300 RC Leiden, The Netherlands, ${ }^{1}$ Department of Internal Medicine, St Elisabeth Hospital, Tilburg, The Netherlands, ${ }^{2}$ Department of Endocrinology and Metabolism, Academic Medical Center, University of Amsterdam, Amsterdam, The Netherlands, ${ }^{3}$ Department of Internal Medicine, Medical Spectrum Twente, Enschede, The Netherlands and ${ }^{4}$ Department of Internal Medicine, Isala Clinics, Zwolle, The Netherlands

(Correspondence should be addressed to N E Kokshoorn; Email: n.e.kokshoorn@lumc.nl)

\begin{abstract}
Objective: Hypopituitarism after traumatic brain injury (TBI) is considered to be a prevalent condition. However, prevalence rates differ considerably among reported studies, due to differences in definitions, endocrine assessments of hypopituitarism, and confounding factors, such as timing of evaluation and the severity of the trauma.

Aim: To evaluate the prevalence of hypopituitarism in a large cohort of TBI patients after long-term follow-up using a standardized endocrine evaluation.

Study design: Cross-sectional study.

Patients and methods: We included 112 patients with TBI, hospitalized for at least 3 days and duration of follow-up $>1$ year after TBI from five (neurosurgical) referral centers. Evaluation of pituitary function included fasting morning hormone measurements and insulin tolerance test $(n=90)$ or, when contraindicated, ACTH stimulation and/or CRH stimulation tests and a GH releasing hormonearginine test $(n=22)$. Clinical evaluation included quality of life questionnaires.

Results: We studied 112 patients (75 males), with median age 48 years and mean body mass index (BMI) $26.7 \pm 4.8 \mathrm{~kg} / \mathrm{m}^{2}$. Mean duration of hospitalization was 11 (3-105), and $33 \%$ of the patients had a severe trauma (Glasgow Coma Scale <9) after TBI. The mean duration of follow-up was 4 (1-12) years.

Hypopituitarism was diagnosed in $5.4 \%$ (6/112) of patients: severe GH deficiency $(n=3)$, hypogonadism $(n=1)$, adrenal insufficiency $(n=2)$. Patients diagnosed with pituitary insufficiency had significantly higher BMI $(P=0.002)$.

Conclusion: In this study, the prevalence of hypopituitarism during long-term follow-up after TBI was low. Prospective studies are urgently needed to find reliable predictive tools for the identification of patients with a significant pre-test likelihood for hypopituitarism after TBI.
\end{abstract}

European Journal of Endocrinology $165225-231$

\section{Introduction}

Traumatic brain injury (TBI) is common and an important cause of death, especially among adolescents in developed countries. In the last decade, pituitary insufficiency has emerged as an important sequel following TBI, potentially influencing short- and longterm morbidity. After TBI, many patients experience persistent, invalidating complaints that resemble those observed in patients with hypopituitarism, such as impaired cognition, depression, fatigue, and impaired quality of life (QoL) (1-4). Consequently, pituitary insufficiency following TBI may contribute to the problems reported by these patients (4). This condition is important to identify since it can be treated by hormone replacement therapy resulting in improved $\operatorname{QoL}(3,5)$.
However, the actual prevalence of hypopituitarism after TBI in an unselected population is subject to debate. The available cohort studies investigating the prevalence of pituitary insufficiency report a percentage ranging from 15 to $90 \%(6-18)$. There are several explanations for this remarkably wide range in reported prevalence, including differences in inclusion criteria and duration of follow-up since TBI (short- versus longterm follow-up), and the use of different tests, and cutoff values (19).

Therefore, the primary aim of this study was to evaluate the prevalence of hypopituitarism in a large cohort of TBI patients after long-term follow-up, using standardized endocrine evaluation including gold standard tests. The secondary aim was to assess QoL and the contribution of hypopituitarism on QoL. 


\section{Patients and methods}

\section{Study protocol}

We performed a multicenter study in five hospitals across the Netherlands (Leiden University Medical Center, Leiden; Academic Medical Center, Amsterdam; St. Elisabeth Hospital, Tilburg; Isala Clinics, Zwolle; Medical Spectrum Twente, Enschede). Eligible patients were selected from electronic registries of the Departments of Neurology using the following inclusion criteria: confirmed diagnosis of TBI and hospitalization for at least 3 days for head injury at least 1 year prior to endocrine evaluation (to exclude possible hormone alterations mimicking pituitary insufficiency in the early post-trauma period), and age 18-70 years. Exclusion criteria were: medical or psychological problems (not related to TBI) that could disturb interpretation of results, including drug or alcohol abuse, previously known hypothalamic or pituitary dysfunction or history of cranial irradiation or pregnancy. Details on trauma severity were derived from the medical records. The Glasgow Coma Scale (GCS) at hospitalization defined the trauma severity. A GCS score of 13-15 indicates mild trauma; between 9 and 12, moderate trauma; and $<9$, severe trauma $(20,21)$. Ethical approval was obtained by the Medical Ethics Committees of all centers, and all patients gave written informed consent.

\section{Patients}

A total of 2350 potential patients were retrieved from the electronic databases that had been diagnosed with TBI. The electronic patient records of these patients were retrieved in the Departments of Neurology of all participating hospitals. However, 1960 patients did not meet the abovementioned inclusion criteria and were excluded. The remaining 390 patients were invited to participate. The response rate was $\sim 70 \%$. Of the 390 patients, 278 could not be included for various reasons: not willing to participate $(30 \%)$, not meeting the inclusion criteria (13\%; either 2 days of hospitalization, drug or alcohol abuse, or medication that could not be stopped) or loss to follow up. Ultimately, we included a total of 112 patients in the study (Fig. 1; Table 1).

\section{Endocrine evaluation}

Blood was sampled for the assessment of basal and stimulated hormone concentrations between 0800 and $0900 \mathrm{~h}$ after an overnight fast. All patients rested $30 \mathrm{~min}$ prior to testing after insertion of an indwelling catheter in a large forearm vein. Baseline samples were drawn for analyses of cortisol, free thyroxine $\left(\mathrm{FT}_{4}\right), \mathrm{TSH}$, testosterone (men), estradiol ( $\mathrm{E}_{2}$; women), LH, FSH, prolactin (PRL), GH, and IGF1. Oral contraceptives were discontinued for at least 6 weeks before testing.

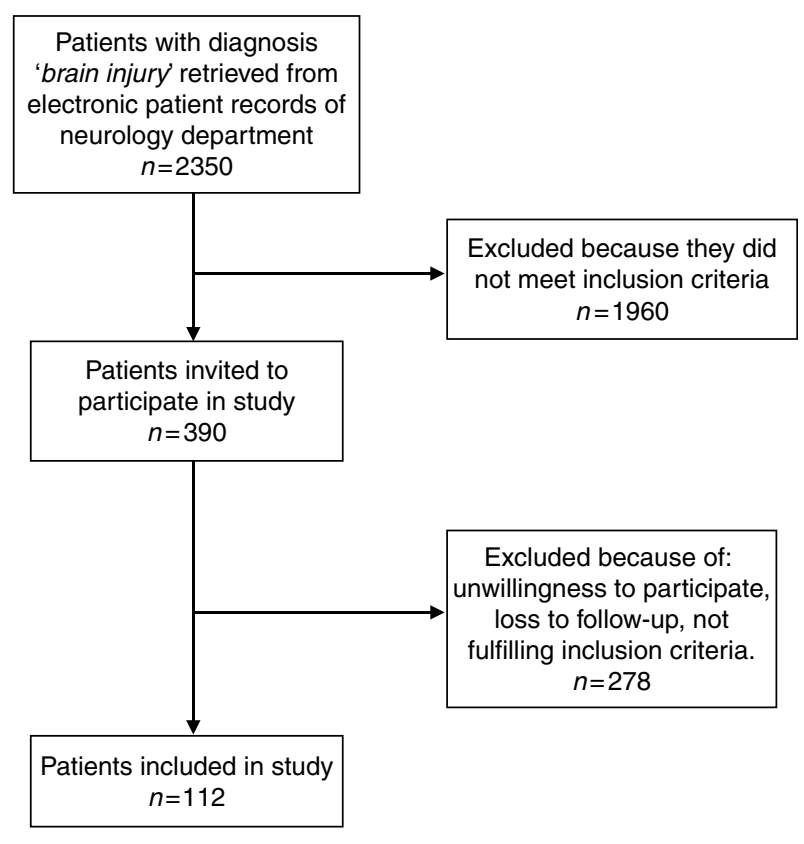

Figure 1 Flowchart of inclusion of patients.

The hypothalamic-pituitary-adrenal (HPA) and GH-IGF1 axes were evaluated by an insulin tolerance test (ITT), unless contraindicated, or alternatively by $\mathrm{ACTH} / \mathrm{CRH}$ and GH releasing hormone (GHRH) stimulation tests. An ACTH test (1 or $250 \mu \mathrm{g}$ Synacthen i.v., Novartis Pharma BV), with measurement of cortisol at $T=-5,30$, and $60 \mathrm{~min}$, was performed routinely in all patients prior to the ITT to ensure sufficient adrenal function. ITT was performed by administering soluble insulin i.v. (0.10 U/kg, Actrapid, Novo, Alphen aan de Rijn, The Netherlands) to induce hypoglycemia (glucose $<2.2 \mathrm{mmol} / \mathrm{l}$ ). Cortisol, ACTH, GH and glucose levels were measured at $T=-15,0,15,30,45,60$, and $90 \mathrm{~min}$. Peak values of $3 \mu \mathrm{g} / \mathrm{l} \mathrm{GH}$ and $>500 \mathrm{nmol} / \mathrm{l}$ cortisol were considered to reflect sufficient pituitary GH and ACTH function. If ITT was contraindicated, a GHRHarginine test was conducted to evaluate GH secretory reserve. Patients received $1 \mu \mathrm{g} / \mathrm{kg}$ GHRH (Ferring BV, Hoofddorp, The Netherlands) and $500 \mathrm{mg} / \mathrm{kg}$ arginine with a maximum of $30 \mathrm{~g}$. GH levels were measured at $T=-15,0,30,45,60,75$, and $90 \mathrm{~min}$. Body mass index (BMI)-adjusted cutoff values of $11.5 \mu \mathrm{g} / \mathrm{l}\left(<25 \mathrm{~kg} / \mathrm{m}^{2}\right)$, $8.0 \mu \mathrm{g} / \mathrm{l}\left(25-30 \mathrm{~kg} / \mathrm{m}^{2}\right)$, and $4.2 \mu \mathrm{g} / \mathrm{l}\left(>30 \mathrm{~kg} / \mathrm{m}^{2}\right)$ were used (22). For the evaluation of the HPA axis when ITT was contraindicated, the response to ACTH stimulation was considered and an additional CRH stimulation test was performed in selected cases (Table 2).

\section{Assays}

GH was measured in participating centers using in-house assays. The measurement of GH has been harmonized in The Netherlands (23), and in all centers, 
Table 1 Baseline characteristics. Data are presented as mean \pm s.D. or median (range).

\begin{tabular}{ll}
\hline & TBI patients $(n=112)$ \\
\hline Gender (M/F) & $75 / 37$ \\
Age (years) & $48(19-69)$ \\
BMI $\left(\mathrm{kg} / \mathrm{m}^{2}\right)$ & $26.7 \pm 4.8$ \\
GCS & \\
Mild & $57 \%$ \\
Moderate-to-severe & $43 \%$ \\
Time since TBI (years) & $4.2 \pm 3.3$ \\
Duration of hospitalization (days) & $11(3-105)$
\end{tabular}

BMI, body mass index; F, female; M, male; TBI traumatic brain injury.

GH was calibrated against the WHO-IRP 98/574 $(1 \mu \mathrm{g} / \mathrm{l}=3.0 \mathrm{mU} / \mathrm{l})$. IGF1 measurement was centralized at the Department of Clinical Chemistry, Sahlgrenska University Hospital, Göteborg, Sweden, using a chemiluminescence immunoassay (DPC, Immulite 2500 system, Siemens Healthcare Diagnostics, Deerfield, IL, USA). The intra- and inter-assay coefficients of variation (CVs) were 4 and 11\% respectively. Reference values based on Brabant et al. (24) were used. Using these IGF 1 values, IGF1 SDS were calculated.

The participating centers used the following in-house assays and cutoff values:

Leiden University Medical Center, Leiden Cortisol, $\mathrm{FT}_{4}$, TSH, LH, FSH, and PRL blood levels were measured by electrochemiluminescence immunoassay (ECLIA), using a Modular E170 (Roche Diagnostics). The maximal inter-assay $\mathrm{CV}$ was $5.0 \%$. ACTH, $\mathrm{GH}$, and IGF1 were determined by immunoluminometric assay using an Immulite 2500 (Siemens Healthcare Diagnostics, Deerfield, IL, USA). The maximal interassay CV was between 5.0 and $10.0 \%$. Glucose levels were measured using a Modular P800 (Roche Diagnostics; $\mathrm{CV}$ is $3 \%$ ). For the measurement of $\mathrm{E}_{2}$ levels, an RIA (Orion Diagnostica, Espoo, Finland) was used (CV was $6 \%$ at $70 \mathrm{pmol} / \mathrm{l})$. The detection limit of $\mathrm{E}_{2}$ was $20 \mathrm{pmol} / \mathrm{l}$. Testosterone was measured using an RIA (Siemens Healthcare Diagnostics; CV was $20 \%$ at $1.0 \mathrm{nmol} / \mathrm{l}$ and $12 \%$ at $14 \mathrm{nmol} / \mathrm{l})$. The detection limit was $0.2 \mathrm{nmol} / \mathrm{l}$.
Academic Medical Center, Amsterdam Plasma LH, TSH, and FSH were analyzed by an automated assay on the E170 of Roche (Roche). The maximal intraand inter-assay $\mathrm{CVs}$ were $<5 \%$. Plasma $\mathrm{FT}_{4}, \mathrm{PRL}$ and $\mathrm{GH}$ were analyzed by fluoroimmunoassay (Delfia, Perkin Elmer, Waltham, MA, USA) using the Delfia 1232 Fluorometer (Perkin Elmer). The maximal intraand inter-assay CVs were 5.1 and $6.8 \%$ for $\mathrm{FT}_{4}, 3.4$ and $5.3 \%$ for PRL, and 3.8 and $6.2 \%$ for GH respectively. Testosterone was analyzed by an in-house RIA. The maximal intra- and inter-assay CVs were 11.8 and $12.8 \%$ respectively. Cortisol was analyzed by chemiluminescence assay using the Immulite 2000 (Siemens Healthcare Diagnostics). The maximal intraand inter-assay CVs were 5.5 and $8.3 \%$ respectively. $\mathrm{E}_{2}$ was measured by RIA (Siemens Healthcare Diagnostics). The intra- and inter-assay CVs were $<20 \%$ (low level) and maximal at $8.6 \%$ (medium level).

\section{St. Elisabeth Hospital, Tilburg and Isala Clinics,} Zwolle Plasma TSH, $\mathrm{FT}_{4}$, PRL, LH, FSH, testosterone, and $\mathrm{E}_{2}$ were analyzed by ECLIA (Modular Analytics E1 70, Roche $\mathrm{GmbH})$. The maximal intra- and interassay CVs as specified by the manufacturer were as follows: TSH, 3.0 and $7.2 \% ; \mathrm{FT}_{4}, 2.0$ and $4.8 \%$; PRL, 1.7 and $2.0 \%$; LH, 1.2 and 2.2\%; FSH, 2.8 and $4.5 \%$; testosterone, 2.8 and $3.2 \%$; and $\mathrm{E}_{2}, 3.6$ and $3.9 \%$. GH was analyzed by a solid-phase, two-site chemiluminescent immunometric assay (Immulite 2000, Siemens Healthcare Diagnostics). The intra- and inter-assay CVs given by the manufacturer were 4.2 and $6.6 \%$ respectively.

Medical Spectrum Twente, Enschede Plasma GH, $\mathrm{LH}, \mathrm{FSH}, \mathrm{PRL}$, testosterone, and $\mathrm{E}_{2}$ levels were analyzed by solid-phase, two-site chemiluminescent immunoassay (Immulite 2000, Siemens Healthcare Diagnostics). The maximal intra- and inter-assay $\mathrm{CVs}$ were as follows: $\mathrm{GH}, 4.2-6.6 \%$; $\mathrm{LH}, 3.6-6.7 \%$; FSH, $2.9-4.1 \%$; PRL, 3.6-7.4\%; testosterone, 10.0-10.3\%; and $\mathrm{E}_{2}$ $7.8-11.0 \%$. Cortisol was analyzed by a solid-phase, competitive chemiluminescent immunoassay (Immulite 2000, Siemens). The intra- and inter-assay CVs were 7.4 and $9.4 \%$ respectively. Plasma TSH and $\mathrm{FT}_{4}$ were

Table 2 Characteristics of patients diagnosed with any pituitary insufficiency.

\begin{tabular}{|c|c|c|c|c|c|c|c|c|c|c|c|}
\hline \multirow{2}{*}{$\begin{array}{l}\text { Patient } \\
\text { no. }\end{array}$} & \multirow[b]{2}{*}{ Sex } & \multirow{2}{*}{$\begin{array}{c}\text { Age } \\
\text { (years) }\end{array}$} & \multirow{2}{*}{$\begin{array}{c}\text { BMI } \\
\left(\mathrm{kg} / \mathrm{m}^{2}\right)\end{array}$} & \multirow{2}{*}{$\begin{array}{l}\text { GCS } \\
\text { score }\end{array}$} & \multirow{2}{*}{$\begin{array}{c}\text { Time } \\
\text { since } \\
\text { TBI } \\
\text { (years) }\end{array}$} & \multicolumn{2}{|c|}{ Dynamic test } & \multirow{2}{*}{$\begin{array}{l}\text { IGF1 } \\
\text { SDS }\end{array}$} & \multirow{2}{*}{$\begin{array}{c}\text { Peak } \\
\text { GH } \\
(\mu \mathrm{g} / \mathrm{l})\end{array}$} & \multirow{2}{*}{$\begin{array}{c}\text { Peak } \\
\text { cortisol } \\
(\mathrm{nmol} / \mathrm{l})\end{array}$} & \multirow[b]{2}{*}{ Deficiency } \\
\hline & & & & & & $\mathrm{GH}$ axis & HPA axis & & & & \\
\hline 1 & $M$ & 65 & 32.2 & 3 & 3 & ITT & ITT & -1.0 & 4.0 & 425 & Cortisol \\
\hline 2 & $M$ & 64 & 29.7 & 7 & 9 & GHRH-arginine & ACTH and CRH & -2.4 & 2.8 & 558 & $\mathrm{GH}$ \\
\hline 3 & $\mathrm{M}$ & 41 & 32.8 & 3 & 4 & GHRH-arginine & ACTH & -0.2 & 9.9 & 590 & Testosterone \\
\hline 4 & $\mathrm{M}$ & 27 & 23.5 & 3 & 10 & GHRH-arginine & ACTH and CRH & -0.7 & 9.4 & 757 & $\mathrm{GH}$ \\
\hline 5 & $\mathrm{~F}$ & 28 & 29 & 15 & 1 & ITT & ITT & 1.2 & 1.9 & 790 & $\mathrm{GH}$ \\
\hline 6 & $\mathrm{~F}$ & 23 & 32.3 & 14 & 3 & ITT & ITT & -0.6 & 2.4 & 395 & $\mathrm{GH}$ and Cortisol \\
\hline
\end{tabular}

BMI, body mass index; F, female; GCS, Glasgow Coma Scale; GHRH, GH releasing hormone; HPA, hypothalamic-pituitary-adrenal axis; ITT, insulin tolerance test; $\mathrm{M}$ male. 
analyzed by ECLIA (Modular Analytics E170, Roche $\mathrm{GmbH})$. The intra- and inter-assay CVs were: 3.0 and $7.2 \%$ for $\mathrm{TSH}$ and 2.0 and $3.6 \%$ for $\mathrm{FT}_{4}$.

\section{QoL assessment}

To assess QoL, the following questionnaires were used:

Hospital anxiety and depression scale (HADS): The HADS questionnaire consists of 14 items pertaining to anxiety and depression, measured on a four-point scale. The scores for the two subscales of anxiety and depression range from 0 to 21 and the total score from 0 to 42 . A high score indicates more severe anxiety or depression (25).

Nottingham Health Profile (NHP): The NHP questionnaire features 38 yes/no questions subdivided in six subscales, i.e. energy, pain, emotional reaction, sleep, physical ability, and social isolation. Scores of the subscales are valued in a range from 0 to 100 . The total score is the mean of all subscales. A high score indicates a worse $\operatorname{QoL}(26,27)$.

Multidimensional fatigue index (MFI-20): The MFI20 questionnaire contains 20 statements to assess fatigue, measured on a five-point scale. The scores of the five subscales of general fatigue, physical fatigue, reduced activity, reduced motivation, and mental fatigue vary from 0 to 20 . A high score indicates more fatigue experienced (28).

Short Form-36 (SF-36): The SF-36 consists of 36 statements or questions evaluating general well-being during the previous 30 days. Scores of the nine subscales of physical functioning, social functioning, role limitations due to physical problems, role limitations due to emotional problems, mental health, vitality, pain, general health perception, and health change are expressed in a 0-100 scale. Higher scores indicate a better $\operatorname{QoL}(29,30)$.

\section{Statistical analysis}

Data were analyzed using PASW Statistics version 17.0.2 (SPSS, Inc., Chicago, IL, USA). All data were presented as mean \pm s.D., unless mentioned. The analysis comprised the comparison of the results between patients with and without pituitary insufficiency.

Groups were compared using an independent samples $t$-test. A $\chi^{2}$ test was used in the case of categorical data. To analyze QoL, the groups were compared using univariate ANOVA with gender and GCS as fixed factors and age as covariate when appropriate. Factors influencing QoL were explored using a Pearson's correlation. A $P$ value of $<0.05$ was considered to be statistically significant.

\section{Results}

\section{Patient demographics}

We included 112 patients (75 males) with a median age of 48 (range 19-69) years (Table 1). Patients were evaluated 1-12 years after trauma (median 3 years). The median duration of hospitalization after TBI had been 11 (3-105) days. BMI was $25(18-43) \mathrm{kg} / \mathrm{m}^{2}$. The causes of TBI had been traffic accidents $(51 \%)$, fall $(38 \%)$, violence $(5 \%)$, and sport- or work-related accidents $(6 \%)$. A total of 36 patients $(32 \%)$ had been diagnosed with a severe trauma and $56 \%$ of the patients $(n=60)$ had a mild trauma, and in four patients, the GCS was not clear from the medical records.

\section{Endocrine evaluation}

Any pituitary insufficiency was diagnosed in only $6 / 112$ patients, resulting in a prevalence rate of $5.4 \%$. Patients with and without pituitary insufficiency were comparable in age and gender, but in patients diagnosed with pituitary insufficiency, BMI was significantly higher $(P=0.02)$. Trauma severity, the duration of follow-up, and the duration of hospitalization were not different between the two groups.

GH-IGF1 axis The ITT was used in $80 \%$ of the patients (90/112) for the evaluation of GH secretory reserve (Fig. 2). Because of contraindications (epilepsy $(n=6)$, ischemic heart disease or rhythm disorders $(n=3)$, other $(n=13))$, the remaining patients were tested using combined GHRH-arginine stimulation test.

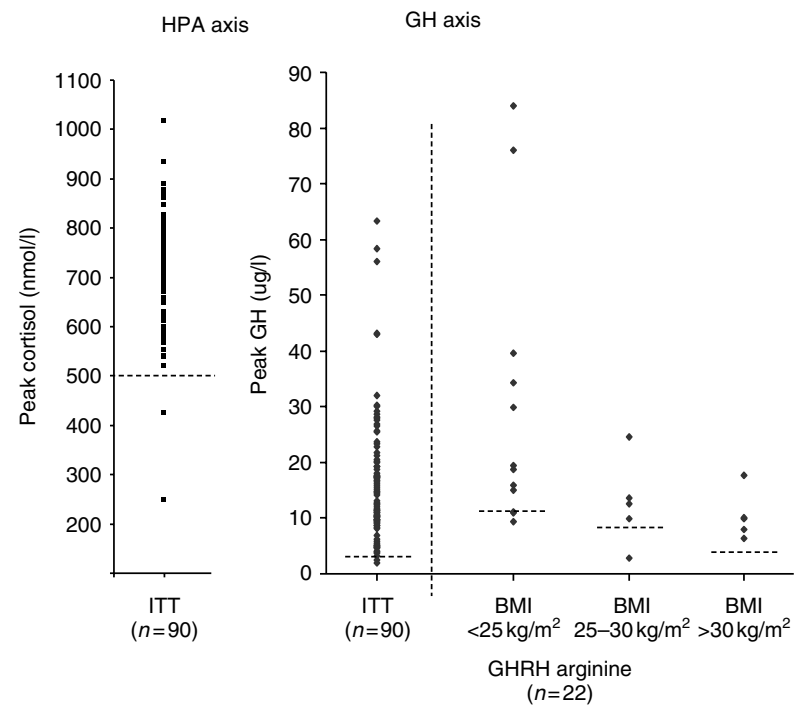

Figure 2 Test results of the stimulation of GH and cortisol secretory reserves using ITT or combined GHRH-arginine test. The dotted horizontal line represents the cutoff value used to define an insufficient response. 
Severe GH deficiency (GHD) was diagnosed in 3.6\% of the patients ( 2 males/2 females, Table 2 ).

HPA axis At baseline, all patients were initially screened with basal morning cortisol levels and a 1 or $250 \mu \mathrm{g} \mathrm{ACTH}$ test to evaluate adrenal function. Subsequently, 90 patients were tested by ITT (Fig. 2). In the remaining 22 patients, the HPA axis was assessed by the results of basal cortisol and the ACTH test. In addition, two patients (diagnosed with other pituitary insufficiencies) were tested also by a $100 \mu \mathrm{g}$ CRH test.

ACTH deficiency was diagnosed in $1.8 \%$ of patients $(2 / 112)$ by insufficient cortisol responses during ITT (Table 2).

Gonadal axis Hypogonadism was diagnosed only in one male patient $(0.9 \%$; T1.9 nmol/l, LH $2.0 \mathrm{IU} / \mathrm{l}$, and FSH $3.0 \mathrm{IU} / \mathrm{l})$.

Thyroid axis We did not diagnose any patient with thyroid insufficiency.

\section{Quality of life}

There were differences in QoL between patients diagnosed with and without pituitary insufficiency. Patients with pituitary insufficiency scored worse on almost all subscales of the QoL questionnaires. More specifically, they scored significantly worse on the subscale 'depression' of the HADS $(P=0.05)$, 'social isolation' of the NHP $(P=0.02)$, 'reduced activity' of the MFI-20 $(P=0.027)$, and 'general health perception' of the SF-36 $(P=0.016$; data not shown).

\section{Discussion}

This study demonstrates that the prevalence of hypopituitarism after TBI in a large patient cohort after long-term follow-up is low. Using a standardized evaluation that included the gold standard test for the evaluation of GH and cortisol secretory reserves in the majority of the patients, we found a prevalence rate of only $5.4 \%$ of any pituitary insufficiency.

This prevalence of hypopituitarism is much lower compared with the prevalence rates reported in the majority of the previous studies (15-90\%) (6-18). This might be explained by the use of different endocrine tests and cutoff values (19). For example, comparable low prevalence of hypopituitarism was found in another study that also used the ITT for screening (15). In addition, when using the combined GHRH-arginine test without BMI-adjusted cutoff values, the prevalence of severe GHD varied between 8 and 20\% (19). A higher $\mathrm{BMI}$ is associated with a decreased $\mathrm{GH}$ response to $\mathrm{GH}$ stimulation tests (22). If BMI-adjusted cutoff values are not used, a higher proportion of patients will be classified as GHD. In addition, age-adjusted cutoff values have recently been reported for the GHRH-arginine test (31).

Differences in the duration of follow-up between TBI and endocrine assessment may also play an important role. Hormone alterations mimicking pituitary insufficiency can be present in the acute phase after trauma. In general, these transient effects are almost exclusively reported only within the first 6 months after TBI $(15$, 32). Therefore, assessment of the function of pituitary axes within this timeframe may result in higher prevalence rates of hypopituitarism. To avoid this bias, we decided to assess patients at least 1 year after the trauma, as suggested in the consensus guidelines for the evaluation and diagnosis of patients with possible GHD (33). In addition to the time interval between TBI and endocrine assessment, the severity of trauma may affect the prevalence rate of pituitary insufficiency $(15,34)$. As shown by Klose et al. (34), increased trauma severity increases the risk of pituitary insufficiency. This may result in higher prevalence rates when patients with a more severe degree of trauma are included. Conversely, prevalence rates of hypopituitarism may decrease when patients with only minor traumas are included (35).

It is important to note that in our study, only a minority of the screened patients fulfilled our inclusion criteria, of which $28.7 \%$ participated. Therefore, by definition, we investigated a pre-selected cohort, which may have affected the results, and, therefore, our conclusions cannot simply be extrapolated to all TBI patients. However, we were able to evaluate the most important clinical characteristics in the majority of the patients $(79 \%)$ who did not participate and found no differences in age during TBI, gender, trauma severity, and duration of hospitalization when compared with those who finally did participate (data not shown). This makes a possible bias, as a result of pre-selection, less likely.

Thus, according to our results, pituitary insufficiency may be a rare complication of TBI in patients evaluated at least 1 year after TBI. Intriguingly, comparable low prevalence rates were found in another study that also used the ITT to evaluate cortisol and GH secretory reserves (32). However, it should be taken into account that there is a high incidence of TBI in the population probably translating in still a high prevalence of posttraumatic hypopituitarism on a population-based level. Besides pre-selection of patients, the use of different tests with different cutoff values has contributed to the differences and large variations in the prevalence rates found in previous studies (19). Our results accentuate that we urgently need consensus for a more uniform and protocol endocrine evaluation after TBI. More importantly, we urgently need prospective studies to find reliable predictors that enable the identification of patients with a significant pre-test likelihood for hypopituitarism. This is of paramount importance, because the presence of pituitary failure, even in a small proportion of patients, is potentially 
treatable, may be lifesaving, and is likely to significantly ameliorate $\operatorname{QoL}(3,5)$.

\section{Declaration of interest}

N E Kokshoorn, W A Nieuwlaat, J Tiemensma, P H Bisschop, R Groote Veldman, F Roelfsema, A A M Franken, M J E Wassenaar, N R Biermasz, and J A Romijn have nothing to disclose. J W A Smit has received research grants from Pfizer. A M Pereira has received research grants and lecture and consultancy fees from Pfizer.

\section{Funding}

This research was supported by an unrestricted grant from Pfizer.

\section{References}

1 Fleminger $\mathrm{S} \&$ Ponsford J. Long term outcome after traumatic brain injury. BMJ 2005331 1419-1420. (doi:10.1136/bmj.331.7530. 1419)

2 van Aken MO \& Lamberts SW. Diagnosis and treatment of hypopituitarism: an update. Pituitary 2005 8 183-191. (doi:10. 1007/s11102-006-6039-z)

3 Blair JC. Prevalence, natural history and consequences of posttraumatic hypopituitarism: a case for endocrine surveillance. British Journal of Neurosurgery 201024 10-17. (doi:10.3109/ 02688690903536637)

4 Klose M, Watt T, Brennum J \& Feldt-Rasmussen U. Posttraumatic hypopituitarism is associated with an unfavorable body composition and lipid profile, and decreased quality of life 12 months after injury. Journal of Clinical Endocrinology and Metabolism 2007 92 3861-3868. (doi:10.1210/jc.2006-1791)

5 Maric NP, Doknic M, Pavlovic D, Pekic S, Stojanovic M, Jasovic-Gasic M \& Popovic V. Psychiatric and neuropsychological changes in growth hormone-deficient patients after traumatic brain injury in response to growth hormone therapy. Journal of Endocrinological Investigation 201033 770-775.

6 Lieberman SA, Oberoi AL, Gilkison CR, Masel BE \& Urban RJ. Prevalence of neuroendocrine dysfunction in patients recovering from traumatic brain injury. Journal of Clinical Endocrinology and Metabolism 200186 2752-2756. (doi:10.1210/jc.86.6.2752)

7 Kelly DF, Gonzalo IT, Cohan P, Berman N, Swerdloff R \& Wang C. Hypopituitarism following traumatic brain injury and aneurysmal subarachnoid hemorrhage: a preliminary report. Journal of Neurosurgery 200093 743-752. (doi:10.3171/jns.2000.93.5. 0743)

8 Bondanelli M, De Marinis L, Ambrosio MR, Monesi M, Valle D, Zatelli MC, Fusco A, Bianchi A, Farneti M \& degli Uberti EC. Occurrence of pituitary dysfunction following traumatic brain injury. Journal of Neurotrauma 200421 685-696. (doi:10.1089/ 0897715041269713)

9 Agha A, Rogers B, Sherlock M, O'Kelly P, Tormey W, Phillips J \& Thompson CJ. Anterior pituitary dysfunction in survivors of traumatic brain injury. Journal of Clinical Endocrinology and Metabolism 2004 89 4929-4936. (doi:10.1210/jc.2004-0511)

10 Popovic V, Pekic S, Pavlovic D, Maric N, Jasovic-Gasic M, Djurovic B, Medic Stojanoska M, Zivkovic V, Stojanovic M, Doknic M, Milic N, Djurovic M, Dieguez C \& Casanueva FF. Hypopituitarism as a consequence of traumatic brain injury (TBI) and its possible relation with cognitive disabilities and mental distress. Journal of Endocrinological Investigation 200427 1048-1054.

11 Leal-Cerro A, Flores JM, Rincon M, Murillo F, Pujol M, GarciaPesquera F, Dieguez C \& Casanueva FF. Prevalence of hypopituitarism and growth hormone deficiency in adults long-term after severe traumatic brain injury. Clinical Endocrinology 200562 525-532. (doi:10.1111/j.1365-2265.2005.02250.x)
12 Schneider HJ, Schneider M, Saller B, Petersenn S, Uhr M, Husemann B, von Rosen F \& Stalla GK. Prevalence of anterior pituitary insufficiency 3 and 12 months after traumatic brain injury. European Journal of Endocrinology $2006154259-265$. (doi:10.1530/eje.1.02071)

13 Tanriverdi F, Senyurek H, Unluhizarci K, Selcuklu A, Casanueva FF \& Kelestimur F. High risk of hypopituitarism after traumatic brain injury: a prospective investigation of anterior pituitary function in the acute phase and 12 months after trauma. Journal of Clinical Endocrinology and Metabolism 200691 21052111. (doi:10.1210/jc.2005-2476)

14 Herrmann BL, Rehder J, Kahlke S, Wiedemayer H, Doerfler A, Ischebeck W, Laumer R, Forsting M, Stolke D \& Mann K. Hypopituitarism following severe traumatic brain injury. Experimental and Clinical Endocrinology E Diabetes $2006114316-321$. (doi:10.1055/s-2006-924254)

15 Klose M, Juul A, Poulsgaard L, Kosteljanetz M, Brennum J \& FeldtRasmussen U. Prevalence and predictive factors of post-traumatic hypopituitarism. Clinical Endocrinology $2007 \quad 67 \quad 193-201$. (doi:10.1111/j.1365-2265.2007.02860.x)

16 Bushnik T, Englander J \& Katznelson L. Fatigue after TBI: association with neuroendocrine abnormalities. Brain Injury 200721 559-566. (doi:10.1080/02699050701426915)

17 Wachter D, Gundling K, Oertel MF, Stracke H \& Boker DK. Pituitary insufficiency after traumatic brain injury. Journal of Clinical Neuroscience 200916 202-208. (doi:10.1016/j.jocn. 2008.01.009)

18 Tanriverdi F, Ulutabanca H, Unluhizarci K, Selcuklu A, Casanueva FF \& Kelestimur F. Three years prospective investigation of anterior pituitary function after traumatic brain injury: a pilot study. Clinical Endocrinology $2008 \mathbf{6 8} 573-579$. (doi:10. $1111 /$ j.1365-2265.2007.03070.x)

19 Kokshoorn NE, Wassenaar MJ, Biermasz NR, Roelfsema F, Smit JW, Romijn JA \& Pereira AM. Hypopituitarism following traumatic brain injury: prevalence is affected by the use of different dynamic tests and different normal values. European Journal of Endocrinology 2010162 11-18. (doi:10.1530/EJE-09-0601)

20 Sternbach GL. The Glasgow Coma Scale. Journal of Emergency Medicine 200019 67-71. (doi:10.1016/S0736-4679(00)00182-7)

21 Teasdale G \& Jennett B. Assessment of coma and impaired consciousness. A practical scale. Lancet 19742 81-84. (doi:10. 1016/S0140-6736(74)91639-0)

22 Corneli G, Di Somma C, Baldelli R, Rovere S, Gasco V, Croce CG, Grottoli S, Maccario M, Colao A, Lombardi G, Ghigo E, Camanni F \& Aimaretti G. The cut-off limits of the $\mathrm{GH}$ response to GH-releasing hormone-arginine test related to body mass index. European Journal of Endocrinology 2005153 257-264. (doi:10. 1530/eje.1.01967)

23 Ross HA. Reporting growth hormone assay results in terms of one consensus recombinant standard preparation offers less than optimal reduction of between-method variation. Clinical Chemistry and Laboratory Medicine 200846 1334-1335. (doi:10.1515/ CCLM.2008.261)

24 Brabant G, von zur Mühlen A, Wuster C, Ranke MB, Kratzsch J, Kiess W, Ketelslegers JM, Wilhelmsen L, Hulthén L, Saller B, Mattsson A, Wilde J, Schemer R, Kann P \& German KIMS Board . Serum insulin-like growth factor I reference values for an automated chemiluminescence immunoassay system: results from a multicenter study. Hormone Research 200360 53-60. (doi:10.1159/000071871)

25 Zigmond AS \& Snaith RP. The hospital anxiety and depression scale. Acta Psychiatrica Scandinavica 198367 361-370. (doi:10. 1111/j.1600-0447.1983.tb09716.x)

26 Hunt SM \& McEwen J. The development of a subjective health indicator. Sociology of Health E Illness 19802 231-246. (doi:10. 1111/1467-9566.ep11340686)

27 Hunt SM, McKenna SP, McEwen J, Backett EM, Williams J \& Papp E. A quantitative approach to perceived health status: a validation study. Journal of Epidemiology and Community Health 198034 281-286. (doi:10.1136/jech.34.4.281) 
28 Smets EM, Garssen B, Bonke B \& De Haes JC. The multidimensional fatigue inventory (MFI) psychometric qualities of an instrument to assess fatigue. Journal of Psychosomatic Research 199539 315-325. (doi:10.1016/0022-3999(94)00125-O)

29 Brazier JE, Harper R, Jones NM, O'Cathain A, Thomas KJ, Usherwood T \& Westlake L. Validating the SF-36 health survey questionnaire: new outcome measure for primary care. BMJ 1992 305 160-164. (doi:10.1136/bmj.305.6846.160)

30 Ware JE Jr \& Sherbourne CD. The MOS36-item short-form health survey (SF-36). I. Conceptual framework and item selection. Medical Care $1992 \quad 30$ 473-483. (doi:10.1097/00005650199206000-00002)

31 Colao A, Di Somma C, Savastano S, Rota F, Savanelli MC, Aimaretti G \& Lombardi G. A reappraisal of diagnosing $\mathrm{GH}$ deficiency in adults: role of gender, age, waist circumference, and body mass index. Journal of Clinical Endocrinology and Metabolism 200994 4414-4422. (doi:10.1210/jc.2009-1134)

32 Klose M, Juul A, Struck J, Morgenthaler NG, Kosteljanetz M \& Feldt-Rasmussen U. Acute and long-term pituitary insufficiency in traumatic brain injury: a prospective single-centre study. Clinical Endocrinology 200767 598-606. (doi:10.1111/j.1365-2265. 2007.02860.x)
33 Ho KK. Consensus guidelines for the diagnosis and treatment of adults with GH deficiency II: a statement of the GH Research Society in association with the European Society for Pediatric Endocrinology, Lawson Wilkins Society, European Society of Endocrinology, Japan Endocrine Society, and Endocrine Society of Australia. European Journal of Endocrinology $2007 \mathbf{1 5 7}$ 695-700. (doi:10.1530/EJE-07-0631)

34 Klose M \& Feldt-Rasmussen U. Does the type and severity of brain injury predict hypothalamo-pituitary dysfunction? Does posttraumatic hypopituitarism predict worse outcome? Pituitary 200811 255-261. (doi:10.1007/s11102-008-0102-x)

35 van der Eerden AW, Twickler MT, Sweep FC, Beems T, Hendricks HT, Hermus AR \& Vos PE. Should anterior pituitary function be tested during follow-up of all patients presenting at the emergency department because of traumatic brain injury? European Journal of Endocrinology 2010162 19-28. (doi:10. 1530/EJE-09-0436)

Received 15 May 2011

Accepted 6 June 2011 